\title{
Apolipoprotein(a) Phenotypes, Lp(a) Concentration and Plasma Lipid Levels in Relation to Coronary Heart Disease in a Chinese Population: Evidence for the Role of the apo(a) Gene in Coronary Heart Disease
}

\author{
Ch. Sandholzer, * E. Boerwinkle, ${ }^{*}$ N. Saha, M. C. Tong, and G. Utermann* \\ ${ }^{*}$ Institute for Medical Biology and Human Genetics, University of Innsbruck, 6020 Innsbruck, Austria; ${ }^{\ddagger}$ Center for Demographic \\ and Population Genetics, University of Texas, Health Science Center, Houston, Texas 77225; \\ and ${ }^{8}$ National University Hospital, Division of Genetics, Singapore 0511, Singapore
}

\begin{abstract}
Elevated lipoprotein(a) (Lp[a]) concentrations are associated with premature coronary heart disease (CHD). In the general population, $\mathrm{Lp}(\mathrm{a})$ levels are largely determined by alleles at the hypervariable apolipoprotein(a) (apola]) gene locus, but other genetic and environmental factors also affect plasma $L p(a)$ levels. In addition, $L p(a)$ has been hypothesized to be an acute phase protein. It is therefore unclear whether the association of $L p(a)$ concentrations with CHD is primary in nature. We have analyzed apo(a) phenotypes, $\mathrm{Lp}$ (a) levels, total cholesterol, and HDL-cholesterol in patients with CHD, and in controls from the general population. Both samples were Chinese individuals residing in Singapore. $L p(a)$ concentrations were significantly higher in the patients than in the population (mean 20.7 \pm 23.9 $\mathrm{mg} / \mathrm{dl}$ vs $8.9 \pm 12.9 \mathrm{mg} / \mathrm{dl})$. Apo(a) isoforms associated with high $L p(a)$ levels (B, S1, S2) were significantly more frequent in the CHD patients than in the population sample $(15.9 \%$ vs 8.5\%, $P<0.01)$. Higher $L p(a)$ concentrations in the patients were in part explained by this difference in apo(a) allele frequencies. Results from stepwise logistic regression analysis indicate that apo(a) type was a significant predictor of CHD, independent of total cholesterol and HDL cholesterol, but not independent of $\mathrm{Lp}(\mathrm{a})$ levels. The data demonstrate that alleles at the apo(a) locus determine the risk for CHD through their effects on $L p(a)$ levels, and firmly establish the role of $L p(a)$ as a primary genetic risk factor for CHD. (J. Clin. Invest. 1992. 89:1040-1046.) Key words: atherosclerosis • risk factor • quantitative genetic trait - population genetics • genetic epidemiology
\end{abstract}

\section{Introduction}

Lipoprotein(a) $(\mathrm{Lp}[\mathrm{a}])^{1}$ is a macromolecular complex in human plasma that is assembled from a low-density lipoprotein (LDL) and apolipoprotein (a) (apo[a]) (1). Shortly after the discovery of the genetic Lp(a) system by Berg (2), it was recognized that high concentrations of $\mathrm{Lp}(\mathrm{a})$ in plasma are asso-

\section{Address correspondence and reprint requests to Prof. Dr. G. Uter- mann, Institut for Medical Biology and Human Genetics, Schopf- strasse 41, Innsbruck, Austria. \\ Received for publication 26 August 1991 and in revised form 8 No- vember 1991}

1. Abbreviations used in this paper: CHD, coronary heart disease; Lp(a), lipoprotein(a).

J. Clin. Invest.

(c) The American Society for Clinical Investigation, Inc.

0021-9738/92/03/1040/07 \$2.00

Volume 89, March 1992, 1040-1046 ciated with coronary heart disease and early myocardial infarction (3-6). This observation was confirmed by numerous studies in different ethnic groups, using different endpoints for definition of coronary artery disease (CAD), and different methods to measure $\mathrm{Lp}(\mathrm{a})$ in plasma (7). The vast majority of these studies are cross-sectional case-control studies. Because of the strong genetic determination of $\mathrm{Lp}(\mathrm{a})$ concentrations, $\mathrm{Lp}(\mathrm{a})$ is widely considered a primary genetic risk factor for coronary heart disease (CHD), despite the lack of any large prospective epidemiological studies.

Originally, Lp(a) was described as a qualitative autosomal dominant trait (2). Later studies showed that $L p(a)$ is a continuous quantitative trait under the control of a single major gene $(8-12)$. The nature of this gene remained elusive until the discovery of a genetic size polymorphism of apo(a) and its association with $\mathrm{Lp}(\mathrm{a})$ levels in plasma (13-15). We have described six different apo(a) isoforms, designated F, B, S1, S2, S3, and S4, that vary in size from $\sim 400$ to over $800 \mathrm{kD}$. In the population, the sizes of apo(a) isoforms are inversely associated with $\mathrm{Lp}(\mathrm{a})$ levels, and in families, apo(a) isoforms and levels cosegregate (13-17). Large isoforms are associated with low Lp(a), and small isoforms with high Lp(a), in plasma. The human apo(a) gene codes for a large protein with a high degree of homology to the plasma zymogen plasminogen $(18,19)$. It contains a protease domain, one so-called kringle 5 domain, and multiple complete, or nearly identical, tandem repeats of a plasminogen like kringle 4 domain. The introns in apo(a) are also highly conserved $(1,20)$ (H. J. Menzel, J. Pfitscher, and G. Utermann, unpublished). The gene locus for apo(a) on chromosome 6 q2.6-2.7 is highly polymorphic. The alleles at this locus determine a genetic size polymorphism of apo(a) $(1,13)$. It has been shown by quantitative Southern blotting, and more recently by pulsed field gel electrophoresis, that this polymorphism results from differences in the number of tandem kringle 4 repeats in the apo(a) gene (20-22) (H. G. Kraft, S. Köchl, and G. Utermann, unpublished). Together, the family, extended population, and molecular genetic studies have shown that the apo(a) gene locus determines both the size of the apo(a) isoform, and the concentration of $L p(a)$ in plasma.

The mechanism by which apo(a) size determines $L p(a)$ concentrations is presently not understood. However, in healthy Caucasians only about $40 \%$ of the variability in $\mathrm{Lp}(\mathrm{a})$ levels is explained by the protein size polymorphism, whereas the rest is presently unexplained. Other genetic, endogenous, and exogenous factors that influence $L p(a)$ levels have been identified, including defective alleles at the LDL-receptor gene locus which result in a two- to threefold elevation (23). Lp(a) levels may also be elevated secondary to disease. In end-stage renal disease, $\mathrm{Lp}(\mathrm{a})$ levels are elevated two- to threefold over controls $(24,25)$ (H. Dieplinger and G. Utermann, unpublished). Fur- 
ther, it has been shown that Lp(a) may behave like an acute phase reactant (26). The development of atherosclerosis is a longlasting process that takes decades before clinical symptoms are manifest. Therefore, the possibility that elevated Lp(a) levels are secondary to the disease process cannot be excluded. The same argument does not apply to the apo(a) isoform phenotypes that represent invariable genetic markers with a significant effect on $\operatorname{Lp}(\mathrm{a})$ levels. The present study was designed to test whether $L p(a)$ is a primary risk factor for CHD. To this end, we determined apo(a) types, $\mathrm{Lp}$ (a) levels, total cholesterol, and HDL-cholesterol in Chinese patients with CHD, and a population sample from Singapore. This population was selected because a much higher fraction of the variability of $L p(a)$ levels is explained by the apo(a) size polymorphism than in Caucasians (27). This demonstrated the expected association of CHD with elevated Lp(a) levels, but, more importantly, it also demonstrated an association of CHD with the apo(a) phenotype.

\section{Methods}

CHD-patients and population sample. Chinese patients with CHD were selected from a series of consecutive patients attending the Singapore Chest and Heart Clinics in the second half of 1990 for suspected CHD. Patients with a positive stress test (Bruce protocol) were evaluated for presence of $\mathrm{CHD}$ by coronary angiography. Inclusion criteria for this study were $50 \%$ or more stenosis of at least one of the major coronary arteries. Patients with less than $50 \%$ stenosis, valve disease, or cardiomyopathy, were excluded. 170 patients (136 men, 34 women) fulfilled the inclusion criteria. For 162 patients, the complete data set was available. Only those have been analyzed.

The healthy population sample (controls) was recruited from subjects who underwent routine medical examination in connection with their employment. Inclusion criteria were normal routine biochemical laboratory tests, a normal resting ECG, absence of a history of cardiovascular disease, and diabetes in the subject and first-degree relatives. 211 subjects (110 men, 101 women) fulfilled the inclusion criteria. Cases and control subjects were from the same ethnic group. The Chinese in Singapore, including both the cases and controls, are Han Chinese from Southern China, and represent the second and third generation of immigration. Fasting blood was drawn into EDTA and centrifuged at low speed. Plasma was stored at $-20^{\circ} \mathrm{C}$ until shipped on dry ice to Innsbruck. All laboratory analysis was carried out within a maximum of 6 mo after blood had been drawn.

Laboratory procedures. Apo(a) phenotyping was performed by SDS-polyacrylamide gel electrophoresis of plasma under reducing conditions, followed by immunoblotting as outlined (15), with slight modification. In brief, $2 \mu \mathrm{l}$ plasma was added to $50 \mu \mathrm{l} 5 \%$ (wt/vol) SDS,

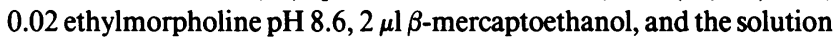
was heated for $3 \mathrm{~min}$ in a microwave oven. $4 \mu \mathrm{l} 1.5 \%$ (wt/vol) bromophenol blue in $10 \%$ glycerol were added. A $5-\mu \mathrm{l}$ aliquot was applied to a $6.6 \%$ polyacrylamide gel prepared and run according to Neville (28). Immunoblotting was performed as described, using the monoclonal anti-apo(a) antibody $1 \mathrm{~A}^{2}(29)$ which does not crossreact with plasminogen. A goat anti-mouse peroxidase conjugate (Dako, Copenhagen, Denmark) was used as second antibody.

Lp(a) quantification was performed by a sandwich-ELISA, essentially as described (29), using a rabbit polyclonal affinity purified antiLp(a) antibody for coating, and the horseradish peroxidase conjugated monoclonal anti-apo(a) antibody $1 \mathrm{~A}^{2}$ for detection. Cholesterol and HDL-cholesterol were determined enzymatically using commercial test kits (Boehringer Mannheim Diagnostics, Mannheim, FRG).

Statistical analysis. Standard statistical methods were used throughout, and were implemented using BMDP Stat. Software, Inc. (Los Angeles, CA) (30). Analysis of these data began with a series of univariate tests to assess the difference of each variable individually between the cases and the control samples from Singapore. These univariate tests were then followed by multivariate analyses to account for the interrelationships among the independent variables as they combine to predict whether an individual one is a case or a control. Routine parametric adjustment of the predicting variables such as $\mathrm{Lp}(\mathrm{a})$, and cholesterol levels for the concomitant effects of age and sex, was not carried out. Rather, adjustment for these relationships were incorporated directly into the multivariate analyses (31). Equality of the apo(a) isoform phenotype frequencies among strata was tested, using a likelihood ratio test. Because the distribution of plasma Lp(a) levels in these (see below) and other data (27) is highly nonnormal, nonparametric statistics such as the Kruskal-Wallis test $(32,33)$ were used to test the equality of the Lp(a) levels among strata. For consistency, the same tests were used to test the equality of the other phenotypes between the cases and controls. Stepwise logistic regression $(31,34)$ using a maximum likelihood procedure (35) was used to assess the relationship between disease status and the set of interrelated predictive variables. Because of their widely accepted role in influencing CHD, gender and age were always included in the logistic model; they were not part of the hypothesis testing hierarchy. Both forward and backward stepping procedures arrived at consistent results for these data (data not shown).

\section{Results}

Apo(a) types and Lp(a) concentrations in a Chinese control population. A description of $\mathrm{Lp}(\mathrm{a})$ and lipid levels in the study population are given in Table I, and the distribution of $L p(a)$ levels in the sample from the Chinese population in Singapore is shown in Fig. $1 A$. The mean $\operatorname{Lp}(\mathrm{a})$ concentration $(8.9 \pm 12.9$ $\mathrm{mg} / \mathrm{dl}$, Table I) is lower in this sample than in the general Caucasian populations (27), and the distribution is highly skewed toward lower levels. Frequencies of apo(a) size isoform phenotypes are given in Table II. Very large isoforms (designated S4) predominate in the Singapore Chinese. The single-band S4 type was, by far, the most common apo(a) isoform phenotype observed in this sample. Taken together, the phenotypes with only high relative molecular mass apo(a) isoforms $(\mathrm{S} 3, \mathrm{~S} 4,0)$ had a relative frequency of $91.4 \%$. Phenotypes with at least one smaller isoform (B, S1, S2) were much less common (8.5\%). There exists an inverse association of apo(a) isoform size with Lp(a) concentrations in plasma (Table III). Lp(a) levels were significantly different between apo(a) types (Kruskal-Wallis test $=81.6,8$ d.f., $P<0.001$ ). Using the $R^{2}$ value from the analysis of variance, $\sim 53 \%$ of the variation in $L p(a)$ concentration was explained by the size polymorphism of apo(a).

These results agree closely with our previous results on an

Table I. Mean Age and Lipid Levels in Chinese CHD Patients and a Control Population Sample

\begin{tabular}{lccc}
\hline & $\begin{array}{c}\text { Controls } \\
n=210\end{array}$ & $\begin{array}{c}\text { CHD patients } \\
n=162\end{array}$ & $P$ \\
\hline Age $y r$ & $37.3 \pm 14.5$ & $57.6 \pm 8.5$ & $<.01$ \\
& $(17-75 \mathrm{yr})$ & $(35-81 \mathrm{yr})$ & \\
$\mathrm{TC} m g / d l$ & $215 \pm 50$ & $244 \pm 56$ & $<.01$ \\
& $(99-369 \mathrm{mg} / \mathrm{dl})$ & $(132-478 \mathrm{mg} / \mathrm{dl})$ & \\
$\mathrm{HDL}-\mathrm{C} m g / d l$ & $48.0 \pm 13.1$ & $34.0 \pm 9.1$ & $<.01$ \\
& $(19-98 \mathrm{mg} / \mathrm{dl})$ & $(12-68 \mathrm{mg} / \mathrm{dl})$ & \\
Lp(a) $m g / d l$ & $8.95 \pm 12.98$ & $20.71 \pm 24.0$ & $<.01$ \\
& $(0.2-75.0 \mathrm{mg} / \mathrm{dl})$ & $(1.0-142.5 \mathrm{mg} / \mathrm{dl})$ &
\end{tabular}



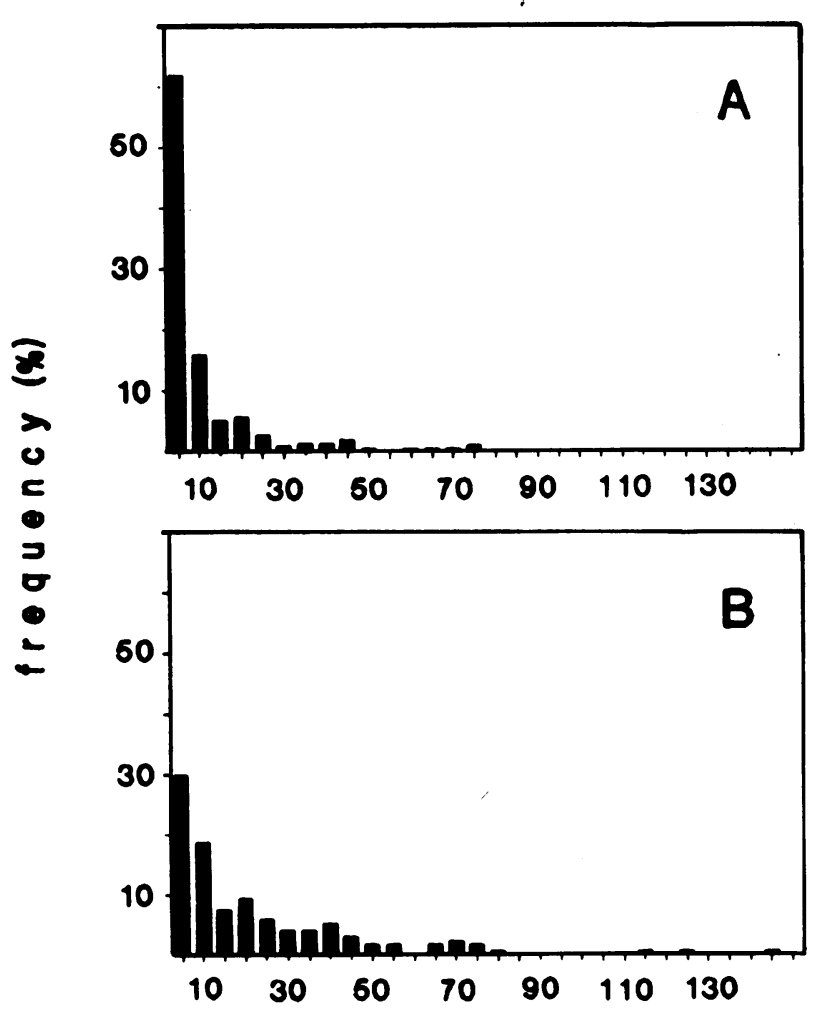

\section{Lpla) Concentration [mg/dl]}

Figure 1. Histograms of $\mathrm{Lp}(\mathrm{a})$ level distributions in a Chinese control population $(A)$, and Chinese patients with $\mathrm{CHD}(B)$ from Singapore.

independent Chinese sample from Singapore (27). Notably, Lp(a) levels in the Chinese with the S4 isoform are lower than in Caucasians, but levels are higher in Chinese S2 and S3 subjects compared with Caucasians (compare Table III) (27). The variance of $L p(a)$ levels within apo(a) isoform phenotypes is smaller than in most other groups. Together, this results in a

Table II. Frequencies (\%) of Apo(a) Phenotypes in Chinese CHD Patients and a Control Population Sample

\begin{tabular}{lcc}
\hline Phenotype & Controls & CHD patients \\
\hline & $(n)^{*}$ & $(n)^{*}$ \\
B & - & - \\
S1 & $1.4(3)$ & $3.7(6)$ \\
S2 & $3.3(7)$ & $6.8(11)$ \\
S3 & $4.8(10)$ & $13.0(21)$ \\
S4 & $56.2(118)$ & $45.7(74)$ \\
0 & $16.7(35)$ & $19.1(31)$ \\
B/S2 & - & $0.6(1)$ \\
B/S4 & - & $1.2(2)$ \\
S1/S2 & $0.95(2)$ & - \\
S2/S3 & $0.95(2)$ & $1.9(3)$ \\
S2/S4 & $1.9(4)$ & $1.2(2)$ \\
S3/S4 & $13.8(29)$ & $6.8(11)$ \\
Total & 210 & 162 \\
& &
\end{tabular}

* Frequency difference between CHD patients and controls by likelihood ratio test; chi-square $=26.3,10$ d.f., $P<0.01$.
Table III. Lipoprotein(a) Concentration (mg/dl $\pm S D$ ) in Relation to Apo(a) Type in Chinese Patients with Coronary Heart Disease (CHD) and a Control Population Sample

\begin{tabular}{lcc}
\hline Phenotype & $\begin{array}{c}\text { Controls } \\
n=210^{*}\end{array}$ & $\begin{array}{c}\text { CHD patients } \\
n=152^{\ddagger}\end{array}$ \\
\hline S1 & $31.7(28.4)$ & $57.9(44.8)$ \\
S2 & $44.2(21.1)$ & $55.4(24.0)$ \\
S3 & $17.2(16.4)$ & $29.2(16.6)$ \\
S4 & $5.7(7.4)$ & $12.1(10.2)$ \\
0 & $2.2(1.8)$ & $3.7(1.7)$ \\
B/S2 & - & $30.5-$ \\
B/S4 & - & $74.7(5.2)$ \\
S1/S2 & $46.0(14.1)$ & - \\
S2/S3 & $11.9(12.2)$ & $88.5(47.7)$ \\
S2/S4 & $31.5(12.2)$ & $60.5(10.6)$ \\
S3/S4 & $10.9(9.2)$ & $19.2(9.1)$ \\
Total & 8.95 & 20.7 \\
& &
\end{tabular}

* Kruskal-Wallis Test $=81.63$; d.f. $8 ; P<0.0001$.

${ }^{\ddagger}$ Kruskal-Wallis Test $=93.77$; d.f. $9 ; P<0.0001$.

relatively larger difference of $L p(a)$ concentrations between the major types, and in a stronger association of apo(a) type with Lp(a) level.

Relationship between Apo(a) types and Lp(a) levels in Chinese patients with CHD. Lp(a) levels, apo(a) phenotype frequencies, and Lp(a) concentrations in the different apo(a) phenotypes in the Chinese patients with CHD are given in Tables II and III, and the distribution of $\mathrm{Lp}(\mathrm{a})$ levels in this sample is shown in Fig. $1 B$. The same inverse relationship of apo(a) size with $\mathrm{Lp}(\mathrm{a})$ level as in the control population was present in the CHD patients (Table III). On the average, patients with large apo(a) isoforms had lower $L p(a)$ levels than those with smaller isoforms. The differences in $\mathrm{Lp}(\mathrm{a})$ concentrations between apo(a) types were highly significant (Kruskal-Wallis test $=93.8$; 9 d.f., $P<0.001$ ).

In the patients, the apo(a) size polymorphism explained $65 \%$ of the variation in $\mathrm{Lp}(\mathrm{a})$ levels. This is higher than in the population sample, and may be due to the increased frequency of those alleles associated with elevated Lp(a) levels in the CHD group (see below).

Thus, $L p(a)$ levels are mainly determined by apo(a) type in both Chinese controls and patients with CHD. This suggests that the differences in levels are in part due to differences in apo(a) allele frequencies.

Comparison of apo(a) type frequencies and $L p(a)$ levels between CHD patients and the control population. Lp(a) concentrations are almost twice as high in the CHD patients than in the general population $(P<0.001)$. Mean $\operatorname{Lp}(\mathrm{a})$ levels are 8.9 $\mathrm{mg} / \mathrm{dl}$ in the population sample, and $20.9 \mathrm{mg} / \mathrm{dl}$ in patients. Average Lp(a) levels for each phenotype in the CHD patient and control groups are shown in Table III. For each variable, levels are significantly higher in the cases than in the population sample. We next asked whether the effects of the apo(a) types on $L p(a)$ levels are the same in both groups. Fig. 2 shows the deviation of $L p(a)$ concentrations from the mean $L p(a)$ level of the respective group for each of the common apo(a) phenotypes. In patients and controls, phenotypic deviations from group means were virtually identical. These data suggest that the effects of apo(a) types on Lp(a) levels are the same in 


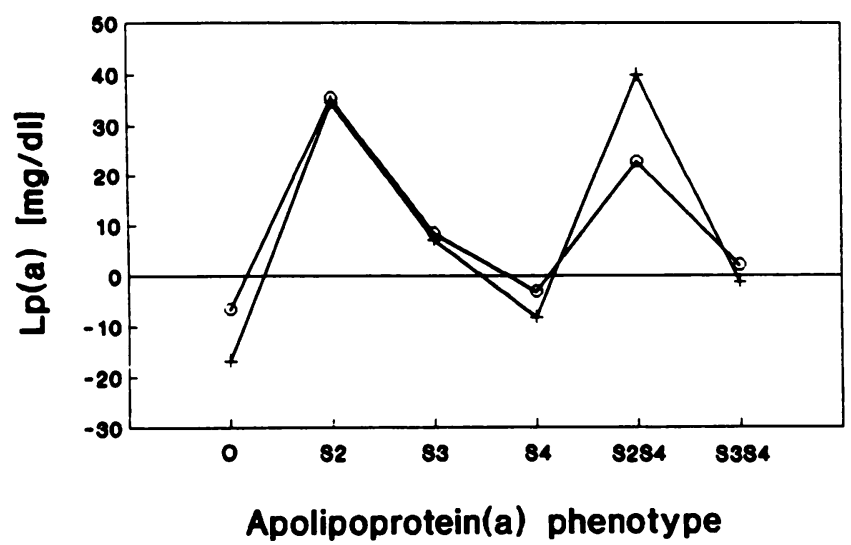

Figure 2. Graphic representation of the deviation of mean Lp(a) concentrations in the common apo(a) types from the respective group means of controls (o), and patients with CHD (+).

both groups. Consistent with this result, using a two-way analysis of variance (36), there is no significant evidence for an interaction effect between apo(a) type and group on Lp(a) levels (data not shown). The central question of this study was whether apo(a) types associated with high $L p(a)$ levels are more frequent in patients than in the control population. A clear and significant difference in apo(a) isoform frequencies between patients and controls was observed (Table II, $P<0.01$ ). Phenotypes associated with high $\mathrm{Lp}(\mathrm{a})$ levels in Caucasians and Chinese were almost twice as frequent in the patients. The small B isoform that is associated with the highest $\mathrm{Lp}(\mathrm{a})$ levels in all populations studied thus far was only seen in the sample of patients. Therefore, higher $L p(a)$ levels in the patients may be at least partially attributable to differences in apo(a) phenotype frequencies between patients and controls. However, the differences in Lp(a) levels between CHD patients and the population sample can not be totally accounted for by the differences in apo(a) type frequencies. Notably, Lp(a) levels were also elevated over controls in each of the common apo(a) phenotypes (Table III). This suggests that the relationship between apo(a) type, Lp(a) level, and CHD may be more complex than anticipated.

We next calculated the odds ratios for $\operatorname{Lp}(a)$ levels and apo(a) types. These ratios represent the relative odds of having CHD or not having CHD for those with increased Lp(a) levels, or certain apo(a) types, respectively. A value of one indicates that there is no association between CHD and Lp(a) levels, or apo(a) types, respectively. Values significantly greater than one measure the degree to which the odds of disease are increased when the risk factor is present. First, subjects were categorized into those with high and low $\mathrm{Lp}(\mathrm{a})$ levels. The histogram of $\mathrm{Lp}(\mathrm{a})$ concentrations in the controls show a natural break at 30 $\mathrm{mg} / \mathrm{dl}$ (Fig. 1). This value also happens to correspond to the 90th percentile. The odds ratio for being in the CHD group for subjects with $\mathrm{Lp}(\mathrm{a})>30 \mathrm{mg} / \mathrm{dl}$ vs those $<30 \mathrm{mg} / \mathrm{dl}$ was 3.975 (Pearson chi-square 20.844, d.f. 1; $P<0.0001$ ). Second subjects were divided into those carrying at least one B, S1, or S2 allele vs those without any of these alleles. The odds ratio for subjects with an allele for one of the low molecular weight isoforms in the CHD group was 1.946 (Pearson chi-square 4.211 , d.f. $1, P<0.05$ ). Thus, subjects with certain apo(a) alleles have a twofold increased risk for CHD.
Total cholesterol, HDL-cholesterol, Lp(a) level, and apo(a) type as predictors of CHD. Total cholesterol concentrations were $215 \pm 50 \mathrm{mg} / \mathrm{dl}$ in the population sample, and $244 \pm 56$ $\mathrm{mg} / \mathrm{dl}$ in the CHD patients, which is significantly higher $(P$ $<0.01$ ). Total cholesterol concentrations in the Chinese control subjects were unexpectedly high and identical to those in Western societies. The reason for this is unknown. Cholesterol levels are, however, typically higher in Singapore Chinese than in Mainland Chinese (37). This probably reflects differences in lifestyle. Whatever the reason for the high cholesterol levels in this particular group, cholesterol levels were even higher in patients with CHD. HDL-cholesterol was significantly lower in the patients $(34 \pm 9 \mathrm{mg} / \mathrm{dl})$ than in the population $(48 \pm 13$ $\mathrm{mg} / \mathrm{dl})$. Thus, the classical lipid risk factors were associated with CHD in the Chinese from Singapore. Stepwise logistic regression was used to assess the independent contribution of the laboratory variable to the prediction of CHD. Because of their widely accepted contribution, sex and age were assumed to be significant predictors, and were automatically incorporated into the logistic risk function. HDL-cholesterol, Lp(a) levels, and total cholesterol, in order, were all independent and significant predictors of disease (Table IV). Apo(a) type was not a significant predictor of disease as long as $\mathrm{Lp}(\mathrm{a})$ levels were in the model $(P=0.106)$. However, if $\operatorname{Lp}(\mathrm{a})$ levels were excluded, $\mathrm{Lp}(\mathrm{a})$ type was a significant predictor of $\mathrm{CHD}(P=0.03)$. This result is consistant with a relationship where apo(a) type determines $L p(a)$ level, and $L p(a)$ level predisposes to disease. Thus, the important conclusion from the logistic regression analysis is that apo(a) genotype is a significant predictor of disease, and is an independent predictor of CHD after considering the traditional risk factors such as age and cholesterol.

\section{Discussion}

This is the first study which firmly establishes a relationship between genetic apo(a) isoforms, Lp(a) levels, and CHD. The comparison between Singapore Chinese patients with CHD, and a Chinese control population, yielded four major results: (a) $\mathrm{Lp}(\mathrm{a})$ levels are significantly higher in CHD patients than in the population; (b) Apo(a) types associated with high Lp(a) levels are more frequent in patients with CHD; $(c) \operatorname{Lp}(a)$ levels are higher in each common phenotype in the CHD patients; and $(d)$ stepwise logistic regression analysis indicates that apo(a) type is a significant predictor of CHD, independent of total cholesterol and HDL-cholesterol, but not independent of Lp(a) levels.

Table IV. Result of a Stepwise Logistic Regression to Predict CHD Status among Chinese in Singapore

\begin{tabular}{lllcc}
\hline \multicolumn{1}{c}{ Variable* } & Coefficient & \multicolumn{1}{c}{ (SE) } & Chi square & $P$ value \\
\hline Constant & 2.22 & 1.15 & - & - \\
Gender & 0.672 & 0.427 & - & - \\
Age & 0.116 & 0.0174 & - & - \\
HDL-cholesterol & 0.162 & 0.0253 & 58.5 & $<0.001$ \\
Lp(a) & 0.0513 & 0.0141 & 20.1 & $<0.001$ \\
Total cholesterol & 0.00933 & 0.00367 & 7.17 & $<0.01$ \\
& & & & \\
\hline
\end{tabular}

* The constant term along with gender and age were forced into the logistic function. The other variables are presented in the order in which they were entered. 
A large number of studies have demonstrated an association of plasma $\mathrm{Lp}(\mathrm{a})$ concentration with $\mathrm{CHD}$ (3-6, 38-41). Most of these have investigated Caucasian populations, but two were performed on Japanese $(6,42)$. With the only exception of one small-nested prospective case-control study (43), all studies relating $\mathrm{Lp}(\mathrm{a})$ levels to $\mathrm{CHD}$ were retrospective casecontrol studies. Such studies may be biased, since the event itself may alter the factor under study. Even prospective studies may be biased in a situation where there is no single event, but rather the longlasting process of atherosclerosis. Such a problem does not exist if the factor under study is a genetic polymorphism that is not changed by disease or throughout life. $\mathrm{Lp}$ (a) levels are widely believed to be largely genetically controlled. However, there is also evidence that several nongenetic factors including postmenopause (44), diabetes mellitus (45, 46), and end-stage renal disease (24) influence $L p(a)$ concentrations in plasma, and some of them are associated with an increased risk for atherosclerosis $(24,44,47-49)$. One report claims that $\mathrm{Lp}(\mathrm{a})$ behaves like an acute phase reactant (26). Therefore, $L p(a)$ concentration cannot be considered an unchangeable, genetically controlled phenotype. Apo(a) phenotypes, however, are a true polymorphism that is not changed by disease or throughout life. Relating apo(a) isoforms to disease, therefore, would definitely show that the apo(a) gene which determines apo(a) type, and influences Lp(a) level, indeed contributes to susceptibility to CHD.

Apo(a) isoforms were originally designated according to their relative mobility, compared with apo B-100 in SDS-polyacrylamide gel electrophoresis, and six isoforms were distinguished (1, 13). Meanwhile, improved separation techniques have enabled us to distinguish more than 10 apo(a) isoforms by SDS-PAGE and immunoblotting $(16,27)$, and more than 20 apo(a) size alleles have been demonstrated by pulsed field gel electrophoresis (20) (H. G. Kraft, S. Köchl, and G. Utermann, unpublished). These alleles and isoforms differ by the number of kringle 4 repeats in the apo(a) gene and protein, respectively. Higher resolution and better separation of isoforms does not, however, affect the linear relationship between apo(a) isoform size and $\mathrm{Lp}(\mathrm{a})$ concentration. The same inverse association between apo(a) isoform size and $\mathrm{Lp}(\mathrm{a})$ levels was obtained in studies based on 6 isoforms (13-15, 27, 50), 11 isoforms (16), 19 alleles (20), and 26 alleles (H. G. Kraft, S. Köchl, and G. Utermann, unpublished). To keep the conditions between the different population samples comparable, we used the same methodology and the same apo(a) isoform standards throughout (27). Isoforms were designated according to our original nomenclature $(1,13)$. Isoforms that did not comigrate exactly with one of the isoform standards were binned with the closest respective isoform in the standard (51). (The apparent molecular weight of apo(a) isoforms were as follows: $F,<400 \mathrm{kD}$; B, $\sim 460 \mathrm{kD} ; \mathrm{S} 1, \sim 520 \mathrm{kD} ; \mathrm{S} 2, \sim 580 \mathrm{kD} ; \mathrm{S} 3, \sim 640 \mathrm{kD} ; \mathrm{S} 4$, $>700 \mathrm{kD}$.)

The results from this study clearly show that apo(a) type frequencies are significantly different between Chinese CHD patients and controls. This is due to a higher frequency of isoforms B, S1, and S2 in the Chinese patients. These isoforms, which are associated with elevated $L p(a)$ levels in all Caucasian and Asian populations, were almost twice as frequent in the CHD patients, compared with the control population. Apo(a) types were also determined in a second independent set of Chinese controls $(n=189)$ and CHD patients $(n=192)$ from Singapore. (Mean age of the CHD-patients in this set was
$57.7 \pm 8.5 \mathrm{yr}$ ). In this second and independent sample, apo(a) type frequencies were also significantly different between patients and controls (likelihood-ratio chi-square $P<0.01$, Table $\mathrm{V})$. As in the first set, it was the low relative molecular mass isoforms (B, S1, S2) associated with high $\mathrm{Lp}(\mathrm{a})$ levels that were significantly overrepresented, and almost twice as frequent in the CHD patients (Table V). No Lp(a) level information was available for this set (samples had been stored for more than 12 mo at $-20^{\circ} \mathrm{C}$, which prohibits reliable determination of $\mathrm{Lp}(\mathrm{a})$ concentrations but not apo(a) phenotyping with our assays). Therefore, no other data from this set were included here. The phenotyping data from this independent set does, however, strongly support our major conclusion from the first set, namely, that alleles at the apo(a) gene locus contribute to the risk for CHD.

We believe that these clear results were obtained because we selected the Chinese population from Singapore for study. Measured variability at the apo(a) gene locus (apo[a] isoforms) explains only a fraction of the inter individual variation in plasma $L p(a)$ levels. Plasma $L p(a)$ concentrations, in turn, contribute to the risk of CHD. Therefore, it will be more difficult to detect a difference in apo(a) isoform frequencies between $\mathrm{CHD}$ patients and controls, compared with differences in $\mathrm{Lp}(\mathrm{a})$ levels. In the Chinese controls, a large fraction of the variability in $\mathrm{Lp}(\mathrm{a})$ levels is predicted by variation at the apo(a) locus $\left(R^{2}\right.$ from the analysis of variance 0.54 ).

Logistic regression analysis demonstrated that apo(a) types are a predictor of $\mathrm{CHD}$, independent of age, sex, total cholesterol, and HDL cholesterol. The odds ratio for Chinese subjects with isoforms $B, S 1$, and $S 2$ suggest that their risk to suffer from $\mathrm{CHD}$ at a mean age of $57 \mathrm{yr}$ is approximately twice that of subjects in which these isoforms are absent. It is important to note that odds ratios were higher for $\mathrm{Lp}(\mathrm{a})$ levels than for apo(a) types, and that apo(a) type was only a predictor for disease when $L p(a)$ levels were omitted from the logistic regression analysis. This strongly suggests that the effect of the apo(a) gene on disease is mediated by $\mathrm{Lp}(\mathrm{a})$ level, and not directly by apo(a) type. This implies that apo(a) phenotyping is not recommended for CHD risk assessment in practical medicine. $\mathrm{Lp}(\mathrm{a})$ concentrations are sufficient, and superior to isoform determination for the prediction of CHD risk. In this context, another observation is noteworthy. $\mathrm{Lp}(\mathrm{a})$ levels in CHD patients were elevated within each of the common apo(a) phenotypic classes. On the surface, this result may seem counterintuitive if one

Table V. Frequencies (\%) of Subjects with Low and High $M_{r}$ Isoforms in the Two Independent Sets of Chinese Patients with Coronary Heart Disease (CHD) and Controls from the General Population

\begin{tabular}{lccccc}
\hline & \multicolumn{2}{c}{ Set 1 } & & \multicolumn{2}{c}{ Set 2 } \\
\cline { 2 - 3 } \cline { 5 - 6 } & Controls & CHD & & Controls & CHD \\
\hline Isoforms & $n=210$ & $n=162$ & $n=189$ & $n=193$ \\
B/S1/S2* & 8.5 & 15.9 & 9.5 & 18.7 \\
S3/S4/0 & 91.5 & 84.1 & & 90.5 & 81.3 \\
$\begin{array}{l}\text { Likelihood ratio } \\
\quad \text { chi-square }\end{array}$ & \multicolumn{2}{c}{$P<0.01$} & & \multicolumn{2}{c}{$P<0.01$}
\end{tabular}

* All subjects with either of the isoforms $B, S 1$, and $\mathrm{S} 2$.

${ }^{\ddagger}$ All subjects with only S3 or S4 isoforms or with Null type. 
assumes that the elevated average $\operatorname{Lp}(\mathrm{a})$ level in the patients was attributable to an increased frequency of certain apo(a) isoforms. However, it does not contradict our hypothesis that differences in apo(a) isoform frequencies contribute to $\mathrm{Lp}(\mathrm{a})$ level differences, and, in fact, might be expected if one considers some features of the $\mathrm{Lp}(\mathrm{a}) / \mathrm{apo}(\mathrm{a})$ system. Two points are relevant to this discussion. First, the relationship between apo(a) type and $\operatorname{Lp}(\mathrm{a})$ level is not strict $(1,50)$. An isoform of the same size may be associated and cosegregated with high $\mathrm{Lp}$ (a) levels in one, and with low levels in another family (H. G. Kraft, S. Köchl, Ch. Sandholzer, and G. Utermann, unpublished); second, apo(a) alleles have an additive effect on $\mathrm{Lp}(\mathrm{a})$ levels $(1,14,50)$. Thus, there may be more true homozygotes among the patients, and also more subjects with isoforms that are associated with levels in the higher range of the respective type. Both phenomena would result in an increase of the typespecific Lp(a) levels in CHD patients over controls. Thus, finding both a higher frequency of apo(a) isoforms $\mathrm{B}, \mathrm{S} 1$, and S2 that are associated with high $\mathrm{Lp}(\mathrm{a})$ levels in the general population, and a higher mean concentration of $L p(a)$ in a given phenotype, is compatible with the postulated relationship between apo(a) isoforms, Lp(a) levels, and the risk for CHD. This does not exclude the possibility that other factors, genetic or nongenetic, that are unrelated to the apo(a) locus, might also contribute to the elevated $\mathrm{Lp}(\mathrm{a})$ levels in CHD patients. Mutations at the LDL-receptor locus that cause familial hypercholesterolemia have been shown to result in elevated Lp(a) levels (23). Other yet unidentified genes may also raise $L p(a)$ concentrations and increase the risk for CHD. Thus, the elevated typespecific $L p(a)$ levels in the CHD patients may well result from the operation of both mechanisms.

We conclude that $L p(a)$ may be an important predictor of CHD in Singapore Chinese, and that high Lp(a) concentrations in this population are genetically determined.

\section{Acknowledgments}

We thank Linda Fineder for expert technical assistance, and Eva Dollinger for typing the manuscript.

This work was supported by the Fonds zur Förderung der Wissenschaftlichen Forschung in Österreich (grant S 4610 to G. Utermann).

\section{References}

1. Utermann, G. 1989. The mysteries of lipoprotein(a). Science (Wash. DC). 246:904-910.

2. Berg, K. 1963. A new serum type system in man: the Lp-system. Acta. Pathol. Microbiol. Scand. 59:369-382.

3. Dahlen, G., K. Berg, T. Gillnas, and C. Ericson. 1975. Lp(a) lipoprotein/ prebeta 1,-lipoprotein in Swedish middle-aged males and in patients with coronary heart disease. Clin. Genet. 7:334.

4. Dahlen, G. H., J. R. Guyton, M. Attar, J. A. Farmer, J. A. Kautz, and A. M. Jr. Gotto. 1986. Association of levels of lipoprotein Lp(a), plasma lipids, and other lipoproteins with coronary artery disease documented by angiography. Circulation. 74:758-765.

5. Kostner, G. M., P. Avogaro, G. Cazzolato, E. Marth, G. Bittolo-Bon, and G. B. Quinci. 1981. Lipoprotein lp (a) and the risk for myocardial infarction. Atherosclerosis. 38:51-61.

6. Rhoads, G. G., G. Dahlen, K. Berg, N. E. Morton, and A. L. Dannenberg. 1986. Lp (a) lipoprotein as a risk factor for myocardial infarction. JAMA (J. Am. Med. Assoc.). 256:2540-2544.

7. Scanu, A. M., and G. M. Fless. 1990. Lipoprotein (a). Heterogeneity and biological relevance. J. Clin. Invest. 85:1709-1715.

8. Sing, C. F., J. S. Schultz, and D. C. Shreffler. 1974. The genetics of the LP antigen. II. A family study and proposed models of genetic control. Ann. Hum. Genet. 38:47-56.
9. Hasstedt, S. J., and R. R. Williams. 1986. Three alleles for the quantitative Lp (a). Genet. Epidemiol. 3:53-55.

10. Hasstedt, S. J., D. E. Wilson, C. Q. Edwards, W. N. Cannon, D. Carmelli, and R. R. Williams. 1983. The genetics of quantitative plasma Lp (a): analysis of a large pedigree. Am. J. Med. Genet. 16:179-188.

11. Iselius, L., G. Dahlen, U. de Faire, and T. Lindman. 1981. Complex segregation analysis of the $\mathrm{Lp}(\mathrm{a})(\mathrm{pre}-\beta)$-lipoprotein trait. Clin. Genet. 20:147151 .

12. Morton, N. E., K. Berg, G. Dahlen, R. E. Ferrel, and G. G. Rhoads. 1985 Genetics of the Lp lipoprotein in Japanese-Americans. Genet. Epidemiol. 2:113121.

13. Utermann, G., H. J. Menzel, H. G. Kraft, H. C. Duba, H. G. Kemmler, and C. Seitz. 1987. Lp (a) glycoprotein phenotype. Inheritance and relation to lp (a)-lipoprotein cocentration in plasma. J. Clin. Invest. 80:458-465.

14. Utermann, G., H. G. Kraft, H. J. Menzel, T. Hopferwieser, and C. Seitz. 1988. Genetics of the quantitative Lp (a) lipoprotein trait. I. relation of Lp (a) glycoprotein phenotypes to $\mathrm{Lp} \mathrm{(a)} \mathrm{lipoprotein} \mathrm{concentrations} \mathrm{in} \mathrm{plasma.} \mathrm{Hum.}$ Genet. 78:41-46.

15. Utermann, G., Ch. Duba, and H. J. Menzel. 1988. Genetics of the quantitative $\mathbf{L p}(\mathrm{a})$ lipoprotein trait II Inheritance of $\mathrm{Lp}(\mathrm{a})$ glycoprotein phenotypes. Hum. Genet. 78:47-50.

16. Gaubatz, J. W., K. I. Ghanem, J. Guevara, Jr., M. L. Nava, W. Patsch, and J. D. Morrisett. 1990. Polymorphic forms of human apolipoprotein[a]: Inheritance and relationship of their molecular weights to plasma levels of lipoprotein[a]. J. Lipid Res. 31:603-613.

17. Drayna, D. T., R. A. Hegele, P. E. Hass, L. L. Wu, M. Emi, D. L. Eaton, R. M. Lawn, R. R. Williams, R. L. White, and J. M. Lalouel. 1988. Genetic linkage between lipoprotein (a) phenotype and a DNA polymorphism in the plasminogen gene. Genomics. 3:230-236.

18. McLean, J. W., J. E. Tomlinson, W-J. Kuang, D. L. Eaton, E. Y. Chen, G. M. Fless, A. M. Scanu, and R. M. Lawn. 1987. cDNA sequence of human apolipoprotein (a) is homologous to plasminogen. Nature (Lond.). 300:132-137.

19. Kratzin, H., V. W. Armstrong, M. Niehaus, N. Hilschman, and D. Seidel. 1987. Structural relationship of an apolipoprotein (a) phenotype $(570 \mathrm{kDa})$ to plasminogen: homologous kringle domains are linked by carbohydrate-rich regions. Biol. Chem. Hoppe-Seyler. 368:1533-1544.

20. Lackner, C., E. Boerwinkle, C. C. Leffert, T. Rahmig, and H. H. Hobbs. 1991. Molecular basis of apolipoprotein (a) isoform size heterogeneity as revealed by pulsed-field gel electrophoresis. J. Clin. Invest. 87:2153-2161.

21. Gavish, D., N. Azrolan, and J. L. Breslow. 1989. Plasma Lp(a) concentration is inversely correlated with the ratio of kringle IV/kringle V encoding domains in the apo(a) gene. J. Clin. Invest. 84:2021-2027.

22. Lindahl, G., E. Gersdorf, H. J. Menzel, M. Seed, S. Humphries, and G. Utermann. 1990. Variation in the size of human apolipoprotein(a) is due to a hypervariable region in the gene. Hum. Genet. 84:563-567.

23. Utermann, G., F. Hoppichler, H. Dieplinger, M. Seed, G. Thompson, and E. Boerwinkle. 1989. Defects in the LDL receptor gene affect Lp (a) lipoprotein levels: Multiplicative interaction of two gene loci associated with premature atherosclerosis. Proc. Natl. Acad. Sci. USA. 86:4171-4174.

24. Parra, H. J., H. Mezdour, C. Cachera, M. Dracon, A. Tacquet, and J. C. Fruchard. 1987. Lp(a) lipoprotein in patients with chronic renal failure treated by hemodialysis. Clin. Chem. 33:721-721.

25. Takegoshi, T., T. Haba, J. Hirai, C. Kitoh, T. Saga, Y. Yamazaki, and H. Mabuchi. 1990. Alterations of lipoprotein(a) in patients with diabetic nephropathy. Atherosclerosis. 83:99-100.

26. Maeda, S., A. Abe, M. Seishima, K. Makino, A. Noma, and M. Kawade. 1989. Transient changes of serum lipopiotein(a) as an acute phase protein. Atherosclerosis. 78:145-150.

27. Sandholzer, C., D. M. Hallman, N. Saha, G. Sigurdsson, C. Lackner, A Császár, E. Boerwinkle, and G. Utermann. 1991. Effects of the apolipoprotein(a) size polymorphism on the lipoprotein(a) concentration in 7 ethnic groups. Hum. Genet. 86:607-614.

28. Neville, D. M. 1971. Molecular weight determination of protein dodecylsulfate complexes by gel electrophoresis in a discontinuous buffer system. J. Biol. Chem. 246:6328-6334.

29. Menzel, H.-J., H. Dieplinger, C. Lackner, F. Hoppichler, J. K. Lloyd, D. R. Muller, C. Labeur, P. J. Talmud, and G. Utermann. 1990. Abetalipoproteinemia with an ApoB-100-lipoprotein(a) glycoprotein complex in plasma. Indication for an assembly defect. J. Biol. Chem. 265:981-986.

30. Dixon, W. J. 1990. BMDP Statistical Software Manual. University of California Press, Los Angeles.

31. Conover, W. J. 1980. Practical Nonparametric Statistics. John Wiley, New York.

32. Daniel, W. W. 1990. Applied Nonparametric Statistics. PWS-Kent Publishing Co., Boston.

33. Kahn, H. A., and C. T. Sempos. 1989. Statistical Methods in Epidemiology. Oxford University Press, New York.

34. Afif, A. A., and V. Clark. 1990. Computer-Aided Multivariate Analyses. Lifetime Learning Publications, Belmont, CA.

35. Jennrich, R. I., and R. H. Moore. 1975. Maximum Likelihood Estimation 
by Means of Nonlinear Least Squares. BMDP Technical Report 9. BMDP Statistical Software, Inc., Los Angeles.

36. Scheffe, H. 1959. The analysis of variance. John Wiley and Sons Inc. New York.

37. Saha, N. 1987. Serum high density lipoprotein cholesterol, apolipoprotein A-I, A-II and B levels in Singapore ethnic groups. Atherosclerosis. 68:117-121.

38. Armstrong, V. W., P. Cremer, E. Eberle, A. Manke, F. Schulze, H. Wieland, H. Kreuzer, and D. Seidel. 1986. The association between serum Lp (a) concentrations and angiographically assessed coronary atherosclerosis-dependence on serum LDL-levels. Atherosclerosis. 62:249-257.

39. Sandkamp, M., H. Funke, H. Schulte, E. Köhler, and G. Assmann. 1990. Lipoprotein(a) is an independent risk factor for myocardial infarction at a young age. Clin. Chem. 36:20-23.

40. Hearn, J. A., S. J. DeMaio, Jr., G. S. Roubin, M. Hammarstrom, and D. Sgoutas. 1990. Predictive value of lipoprotein (a) and other serum lipoproteins in the angiographic diagnosis of coronary artery disease. Am. J. Cardiol. 66:11761180.

41. Genest, J., Jr., J. L. Jenner, J. R. McNamara, J. M. Ordovas, S. R. Silberman, P. W. F. Wilson, and E. J. Schaefer. 1991. Prevalence of lipoprotein (a) [Lp(a)] excess in coronary artery disease. Am. J. Cardiol. 67:1039-1045.

42. Murai, A., T. Miyahara, N. Fujimoto, M. Matsuda, and M. Kameyama. 1986. $\mathrm{Lp}(\mathrm{a})$ lipoprotein as a risk factor for coronary heart disease and cerebral infarction. Atherosclerosis. 59:199-204.

43. Rosengren, A., L. Wilhelmsen, E. Eriksson, B. Risberg, and H. Wedel. 1990. Lipoprotein (a) and coronary heart disease: A prospective case-control study in a general population sample of middle aged men. Br. Med. J. 301:12481251.

44. Schriewer, H., G. Assmann, and M. Sandkamp. 1984. The relationship of lipoprotein(a) $(\mathrm{Lp}(\mathrm{a}))$ to risk factors of coronary heart disease: initial results of the prospective epidemiological study on company employees in Westfalia. J. Clin. Chem. Clin. Biochem. 22:591-596.

45. Levitsky, L. L., A. Scanu, and S. H. Gould. 1991. Lipoprotein(a) Levels in Black and White Children and Adolescents with IDDM. Diabetes Care. 14:283287.

46. Haffner, S. M., K. R. Tuttle, and D. L. Rainwater. 1991. Decrease of Lipoprotein(a) With Improved Glycemic Control in IDDM Subjects. Diabetes Care. 14:302-307.

47. Soma, M., R. Fumagalli, R. Paoletti, M. Meschia, M. C. Maini, P. Crosignani, K. Ghanem, J. Gaubatz, and J. D. Morrisett. 1991. Plasma Lp(a) concentration after oestrogen and progestagen in postmenopausal women. Lancet. 337:612-612.

48. Kervinen, K., M. J. Savolainen, and Y. Antero Kesäniemi. 1991. A rapid increase in lipoprotein (a) levels after ethanol withdrawal in alcoholic men. Life Sci. 48:2183-2188.

49. Bruckert, E., P. Davidoff, A. Grimaldi, J. Truffert, P. Giral, R. Doumith, F. Thervet, and J. L. De Gennes. 1990. Increased serum levels of lipoprotein(a) in diabetes mellitus and their reduction with glycemic control. JAMA (J. Am. Med. Assoc.). 263:35-36.

50. Boerwinkle, E., H. J. Menzel, H. G. Kraft, and G. Utermann. 1989. Genetics of the quantitative Lp (a) lipoprotein trait. III. Contribution of Lp (a) glycoprotein phenotypes to normal lipid values. Hum. Genet. 82:73-78.

51. Budowle, B., A. M. Giusti, J. S. Waye, F. S. Baechtel, R. M. Fourney, D. E. Adams, L. A. Presley, H. A. Deadman, and K. L. Monson. 1991. Fixed-bin analysis for statistical evaluation of continuous distributions of allelic data from VNTR loci, for use in forensic comparisons. Am. J. Hum. Genet. 48:841-855. 